\title{
Linkage modification of a zinc oxide photoelectrode prepared with polyethylene glycol for electron transport improvement in dye-sensitized solar cells
}

\author{
SUTTHIPOJ WONGRERKDEE ${ }^{1, *}$, SASIMONTON MOUNGSRIJUN ${ }^{1}$, \\ SUPPHADATE SUJINNAPRAM ${ }^{1}$, SUCHEEWAN KROBTHONG ${ }^{1}$ and SUPAB CHOOPUN ${ }^{2,3,4}$ \\ ${ }^{1}$ Department of Physics, Faculty of Liberal Arts and Science, Kasetsart University, Kamphaeng Saen Campus, \\ Nakhon Pathom 73140, Thailand \\ ${ }^{2}$ Department of Physics and Materials Science, Faculty of Science, Chiang Mai University, Chiangmai 50200, Thailand \\ ${ }^{3}$ Center of Advanced Materials for Printed Electronics and Sensors, Faculty of Science, Chiang Mai University, \\ Chiang Mai 50200, Thailand \\ ${ }^{4}$ Thailand Center of Excellence in Physics (ThEP Center), CHE, Bangkok 10400, Thailand \\ *Author for correspondence (sutthipoj.s@gmail.com)
}

MS received 5 June 2018; accepted 18 November 2018; published online 27 March 2019

\begin{abstract}
The purpose of this study is to synthesize $\mathrm{ZnO}$ aggregate films using simple precipitation with polymer modification for linkage improvement of the $\mathrm{ZnO}$ photoelectrode. The starting materials of zinc acetate solution and ammonia solution were mixed under violent stirring conditions. A portion of the polymer (polyethylene glycol) was slowly added into the mixed solution to obtain the viscous $\mathrm{ZnO}$ precursor. The precursor was then coated onto a fluorine-doped tin oxide substrate and annealed to form $\mathrm{ZnO}$ films. The scanning electron microscopy results revealed the formation of $\mathrm{ZnO}$ aggregates with flower-like microstructures. The appearance of $\mathrm{Zn}$ and $\mathrm{O}$ elements indicated a fair $\mathrm{ZnO}$ formation. The X-ray diffraction patterns and Raman shift confirmed the hexagonal wurtzite crystal structure of the $\mathrm{ZnO}$ aggregates. For dye-sensitized solar cell (DSSC) application, power conversion efficiency was enhanced because of the improved photovoltaic characteristics including the open-circuit voltage, fill factor, series resistance, shunt resistances and recombination resistance, perhaps, due to the large particle size of the $\mathrm{ZnO}$ aggregates and their flower-like microstructures. The flower-like microstructure likely acts as a bridge to link each $\mathrm{ZnO}$ particle. The flower-like microstructure plays the role of an express pathway in electron transport in the DSSC. Therefore, the $\mathrm{ZnO}$ aggregation with a flower-like microstructure has the potential to improve the electron transport for efficiency enhancement of a DSSC.
\end{abstract}

Keywords. $\mathrm{ZnO}$; flower-like; microstructure; electron transport; dye-sensitized solar cell.

\section{Introduction}

$\mathrm{ZnO}$ nanoparticles (NPs) have been used as photoelectrodes in dye-sensitized solar cells (DSSCs) due to their advantages such as high electron mobility, a wide band gap semiconductor, low cost and environmentally friendly [1-3]. $\mathrm{ZnO}$ photoelectrodes play major roles in the functioning of DSSCs including dye adsorption, electron separation and electron transport [4]. Among these, electron transport could be considered as a volatile factor that is decreased due to the electron scattering effect. The effect is due to the presence of many grain boundaries of NP structures [5]. The effect occurs when the electrons transport between the particle-particle connections. After hitting the grain boundary, some electrons may be reflected and the electron transporting direction is deviated from the original direction causing the loss of electron transport. This effect can significantly decrease the DSSC performance. To solve this problem, the structure and connection of $\mathrm{ZnO}$ should be investigated. For example, Wan et al [6] introduced $\mathrm{Bi}_{2} \mathrm{Te}_{3}$ nanosheets (NSs) as a composite photoelectrode to achieve an enhanced DSSC performance. The composite photoelectrode was prepared by mixing $\mathrm{Bi}_{2} \mathrm{Te}_{3}$ NSs and ZnO NPs. The $\mathrm{Bi}_{2} \mathrm{Te}_{3}$ NSs played an important role in improving the charge transport, suppressing charge recombination and also acting as a heat sink to reduce the temperature of the DSSC device. DSSCs fabricated with the composite photoelectrode showed a significant enhancement in the power conversion efficiency (PCE), even though the dye adsorption decreased. Xu et al [1] demonstrated an enhancement of PCE using a double-layered photoelectrode of $\mathrm{ZnO}$ $\mathrm{NPs} / \mathrm{ZnO}$ micro-flowers. The PCE was enhanced due to the improvement in electron transport and light harvesting efficiency. Nevertheless, a reduction of electron recombination was found simultaneously. Song et al [7] showed that a modified double-layered photoelectrode can be used to enhance the DSSC performance. They initially prepared the doublelayered photoelectrode of $\mathrm{ZnO} \mathrm{NPs} / \mathrm{ZnO}$ nanowires, modified with multi-walled carbon nanotubes and $\mathrm{TiCl}_{4}$. A DSSC 


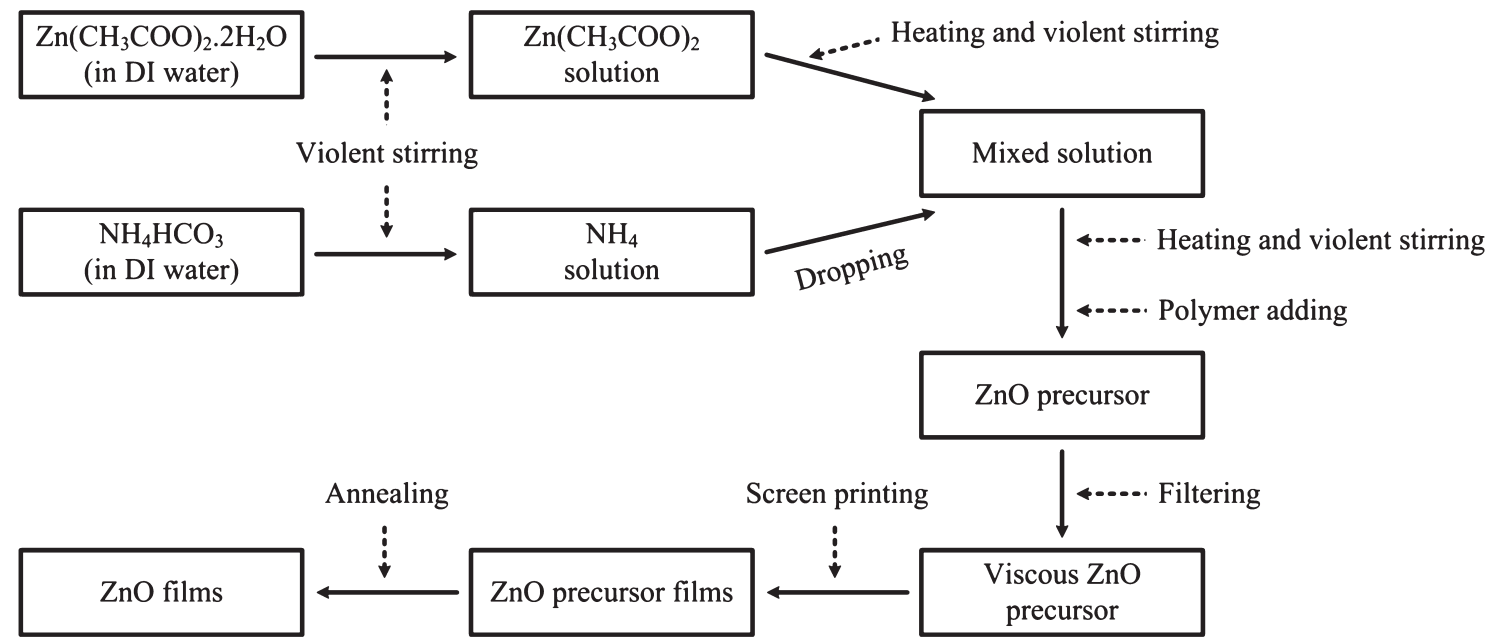

Figure 1. Diagram of $\mathrm{ZnO}$ film preparation.

fabricated with the modified photoelectrode exhibited an excellent enhancement in the PCE achieving 3.8\% compared to that with bar $\mathrm{ZnO}$ NPs (1.5\%). The successful enhancement was due to the co-functions of faster electron transport, less electron recombination and increased dye adsorption. These photoelectrodes modified in multi-steps such as composite materials, or post-treatments produced a successful DSSC application. However, multi-step modification could make the fabrication process difficult and costly. In the current work, $\mathrm{ZnO}$ aggregates with flower-like microstructures synthesized using a simple precipitation process with polymer modification is proposed to reduce the fabrication process. The addition of polyethylene glycol (PEG) is expected to improve the linkage between $\mathrm{ZnO}$ particles during the reaction to obtain $\mathrm{ZnO}$ aggregates with a flower-like microstructure. The structure is believed to provide an express pathway for electron transport in a DSSC. Due to the pathway improvement, the performance of a DSSC fabricated with the $\mathrm{ZnO}$ aggregate photoelectrode could be enhanced.

\section{Experimental}

\subsection{ZnO photoelectrode preparation}

Starting materials of zinc acetate solution and ammonia solution were separately prepared. The zinc acetate solution was prepared by dissolving $1.76 \mathrm{~g}$ zinc acetate dihydrate $\left(\mathrm{Zn}\left(\mathrm{CH}_{3} \mathrm{COO}\right)_{2} \cdot 2 \mathrm{H}_{2} \mathrm{O}\right.$; RCI Labscan $)$ in $20 \mathrm{ml}$ distilled water. The ammonia solution was prepared by dissolving $1.27 \mathrm{~g}$ of ammonium hydrogen carbonate $\left(\mathrm{NH}_{4} \mathrm{HCO}_{3}\right.$; RCI Labscan) in $20 \mathrm{ml}$ distilled water/ethanol mixture (1/1, v/v). Both solutions were violently stirred for $1 \mathrm{~h}$ to form clear solutions. Before mixing, the zinc acetate solution was heated at $70^{\circ} \mathrm{C}$ for $15 \mathrm{~min}$. Next, the ammonia solution was added into the zinc acetate solution drop by drop. After mixing, the polymer modification was carried out by adding $8 \mathrm{~g}$ PEG-4000 into the mixed solution under continuous violent stirring and heating. After $1 \mathrm{~h}$, the solution was cooled down to room temperature and the solution was dropwise added into filter paper for $12 \mathrm{~h}$ to obtain the viscous $\mathrm{ZnO}$ precursor. For $\mathrm{ZnO}$ film preparation, the $\mathrm{ZnO}$ precursor was coated onto fluorine-doped tin oxide (FTO; Sigma-Aldrich) substrate using a screen printing method with an active area of $1 \mathrm{~cm}^{2}$. The thickness was controlled by the template of the screen printing system to around $18 \mu \mathrm{m}$. Next, the precursor films were annealed at $400^{\circ} \mathrm{C}$ for $1 \mathrm{~h}$ to obtain the $\mathrm{ZnO}$ films used as the $\mathrm{ZnO}$ photoelectrode. The steps involved in the preparation of the $\mathrm{ZnO}$ photoelectrode are diagrammatically described in figure 1. For comparison, commercial $\mathrm{ZnO}$ NPs (Nano Materials Technology Co. Ltd., particle size $\sim 20-40 \mathrm{~nm}$ ) were used to prepare referent films with a similar active area and thickness. The preparation details of the $\mathrm{ZnO}$ NP films were described in previous reports $[8,9]$.

\subsection{DSSC fabrication}

Before the DSSC fabrication process, the $\mathrm{ZnO}$ photoelectrode was immersed into N719 solution in the dark for $1 \mathrm{~h}$ to adsorb dye molecules, then rinsed with ethanol and dried in air to form a dye-sensitized photoelectrode. The N719 solution was prepared by dissolving 0.3 mM N719 (Dyesol) into an ethanol/acetone mixture $(1 / 1, \mathrm{v} / \mathrm{v})$ and stirring for $1 \mathrm{~h}$ in the dark. At the same time, the counterelectrode was prepared by dropwise adding Pt solution onto the FTO substrate, spin-coating for $30 \mathrm{~s}$ and annealing at $550^{\circ} \mathrm{C}$ for $1 \mathrm{~h}$. The Pt solution was prepared by dissolving $12 \mathrm{mg} \mathrm{Cl}_{6} \mathrm{H}_{2} \mathrm{Pt}$ (Merck) in $1 \mathrm{ml}$ acetone under sonication for $1 \mathrm{~h}$. For DSSC fabrication, the photoelectrode and counterelectrode were sandwich-fabricated and sealed with polymer films. Finally, the liquid electrolyte was injected into the gap between the 
photoelectrode and the counterelectrode. The electrolyte was prepared by dissolving $0.03 \mathrm{I}_{2}, 0.3 \mathrm{M} \mathrm{LiI}$ and $0.03 \mathrm{M}$ DMPII in acetone-nitride under stirring.

\subsection{Characterization and measurement}

Characterization of the $\mathrm{ZnO}$ photoelectrode was investigated using various techniques. The morphology was observed using scanning electron microscopy (SEM). The chemical composition was detected using energy dispersive spectroscopy (EDS). The crystal structure was investigated using X-ray diffraction pattern (XRD). Raman shift analysis was performed using Raman spectroscopy. Dye adsorption was measured using ultraviolet-visible-near infrared (UV-VisNIR) spectroscopy. The dye-sensitized $\mathrm{ZnO}$ photoelectrode was immersed into $0.1 \mathrm{M} \mathrm{NaOH}$ solution (dissolved in an equal volumetric ratio of distilled water and ethanol) to extract dye molecules. Next, the solution carrying the dye molecules was measured. Photovoltaic characteristics were evaluated using current-voltage $(J-V)$ measurements and electron recombination was investigated using electrochemical impedance spectroscopy (EIS).

\section{Results and discussion}

\subsection{Morphology}

Figure 2 shows the morphology of the $\mathrm{ZnO}$ films prepared from commercial $\mathrm{ZnO}$ NPs ( $\mathrm{ZnO}$ NP films) and synthesized from zinc nitrate with PEG assistance ( $\mathrm{ZnO}$ aggregate films). The $\mathrm{ZnO} \mathrm{NP}$ films (figure $2 \mathrm{a}$ and $\mathrm{b}$ ) and the $\mathrm{ZnO}$ aggregate films (figure 2c and d) showed an apparent difference in their surface morphology. The ZnO NP films had a non-smooth film formation as could be seen from numerous pore positions. The pores at the surface may have formed because of the evaporation of PEG during the annealing process. Note that the high magnification image (figure 2b) shows that the $\mathrm{ZnO}$ NP films were formed with a combination of small $\mathrm{ZnO}$ NPs. For the $\mathrm{ZnO}$ aggregate films (figure 2c), the morphology showed a comparatively larger particle size with sticking-out parts which were the same as a flower-like microstructure. The flower-like microstructure was elongated from one particle reaching the other particle like a bridge for particle-particle linkage. It is believed that the linkage in the $\mathrm{ZnO}$ aggregate films may be modified for better electron transport. Moreover, the high magnification SEM image of $\mathrm{ZnO}$ aggregate films (figure $2 \mathrm{~d}$ ) revealed that the surface of the
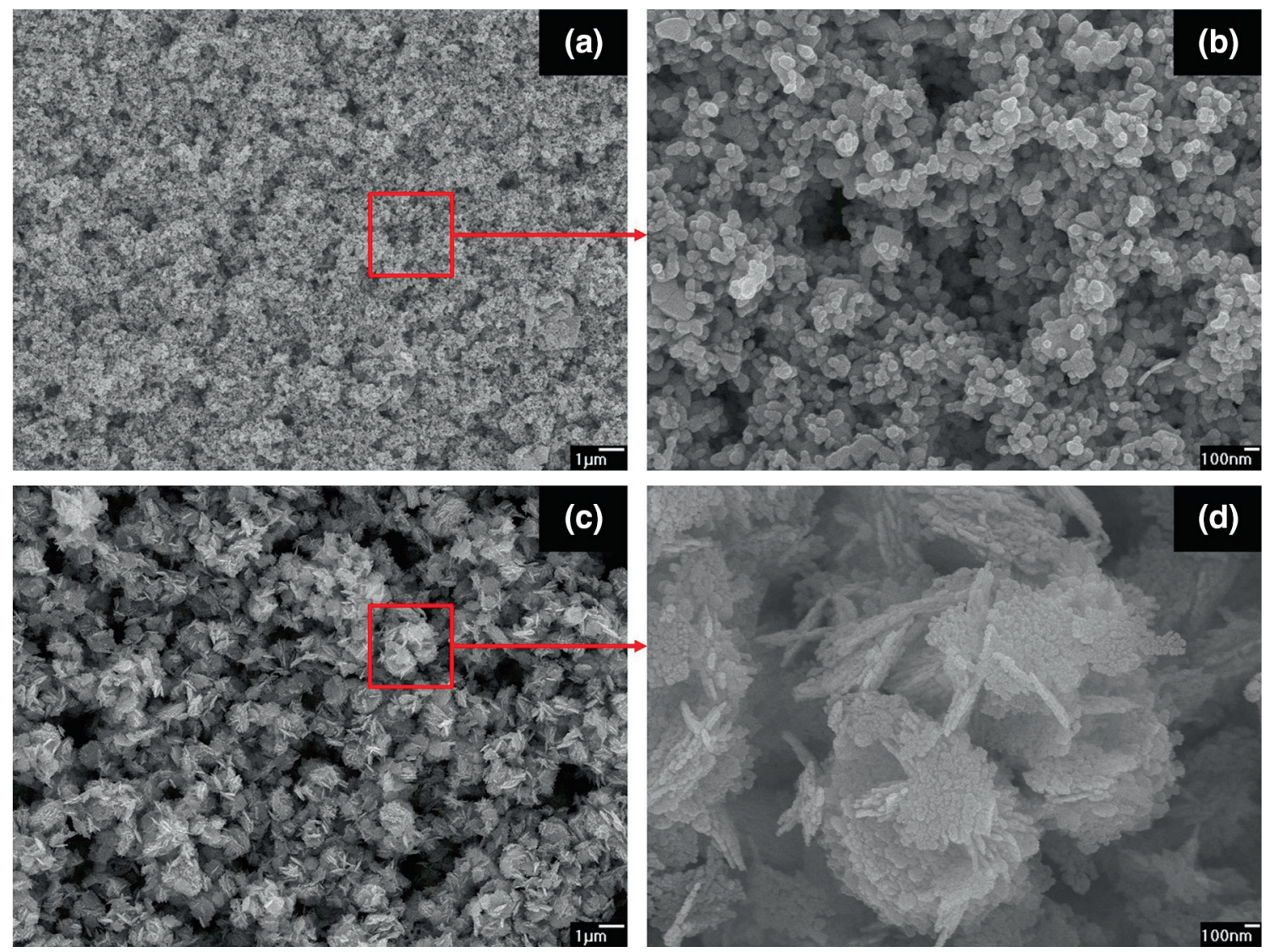

Figure 2. Morphology of $\mathrm{ZnO}$ films prepared from commercial $\mathrm{ZnO}$ NPs (a, b) compared with $\mathrm{ZnO}$ aggregate films (c, d). 
flower-like microstructure consisted of small NP attachments. These attached particles may be formed after flower-like microstructure formation and accumulated over the surface of the flower-like microstructure. To estimate the particle size, the diameters of the $\mathrm{ZnO} \mathrm{NP}$ films and the $\mathrm{ZnO}$ aggregate films were measured using Image-J software as shown in figure 3. The diameters of the $\mathrm{ZnO} \mathrm{NP}$ films and the $\mathrm{ZnO}$ aggregate films were in the range of 36-230 $\mathrm{nm}$ and $0.65-$ $2.10 \mu \mathrm{m}$, respectively. The average diameters were $82.57 \mathrm{~nm}$ and $1.16 \mu \mathrm{m}$, respectively. Generally, chemical processes for $\mathrm{ZnO}$ formation can be described [6,10-12] according to the following equations $[13,14]$ :

$$
\begin{aligned}
& \mathrm{NH}_{4} \mathrm{HCO}_{3} \rightarrow \mathrm{NH}_{3} \cdot \mathrm{H}_{2} \mathrm{O}+\mathrm{CO}_{2} \\
& \mathrm{NH}_{3} \cdot \mathrm{H}_{2} \mathrm{O} \leftrightarrow \mathrm{NH}_{4}^{+}+\mathrm{OH}^{-} \\
& \mathrm{Zn}^{2+}+2 \mathrm{OH}^{-} \rightarrow \mathrm{Zn}(\mathrm{OH})_{2} \\
& \mathrm{Zn}(\mathrm{OH})_{2} \rightarrow \mathrm{ZnO}+\mathrm{H}_{2} \mathrm{O}
\end{aligned}
$$

$\mathrm{ZnO}$ is commonly obtained after the addition of ammonia solution into zinc acetate solution. When the $\mathrm{Zn}^{2+}$ ions reacts with $\mathrm{OH}^{-}$, precipitation of the $\mathrm{Zn}(\mathrm{OH})_{2}$ complexes is obtained via equation (3). These complexes are finally decomposed as $\mathrm{ZnO}$ as shown in equation (4) under the reaction conditions. From the growth mechanism, $\mathrm{ZnO}$ NPs can be obtained under appropriate control of the ammonia concentration. In this work, $\mathrm{ZnO}$ aggregates with flowerlike microstructures were obtained in the presence of PEG. The growth mechanism of the $\mathrm{ZnO}$ aggregates prepared with PEG modification can be described according to the schematic diagram in figure 4. After the addition of PEG into the mixture of zinc acetate solution and ammonia solution, the $\mathrm{Zn}(\mathrm{OH})_{2}$ complexes can easily adsorb PEG because the available $\mathrm{OH}^{-}$groups have the potential to directly bond with PEG. This effect leads to carrying the $\mathrm{Zn}(\mathrm{OH})_{2}$ complexes with polymer chains, and $\mathrm{Zn}^{2+}$ ions may be collected at the same time due to ionic interactions. Under saturation conditions, the $\mathrm{Zn}(\mathrm{OH})_{2}$ complexes and $\mathrm{Zn}^{2+}$ ions are transformed into $\mathrm{ZnO}$ aggregates. After the formation of the $\mathrm{ZnO}$ aggregates, some surface $\mathrm{ZnO}$ may adsorb PEG molecules at the $\mathrm{O}$-site. The effect may cause anisotropic reduction of $\mathrm{ZnO}$ and surface activity reduction. The growth rate of $\mathrm{ZnO}$ at the PEG adsorbed surface will be slowed down which results in a non-homogeneous growth of $\mathrm{ZnO}$. The non-homogeneous growth results in the flower-like microstructure formation which agrees with previous reports [15-17]. Thus, it can be stated that the $\mathrm{ZnO}$ aggregates with flower-like microstructures can be successfully synthesized using a simple precipitation process with PEG modification.

\subsection{Chemical composition}

The chemical composition of the $\mathrm{ZnO}$ films was detected using EDS as shown in figure 5. The $\mathrm{ZnO}$ formation was
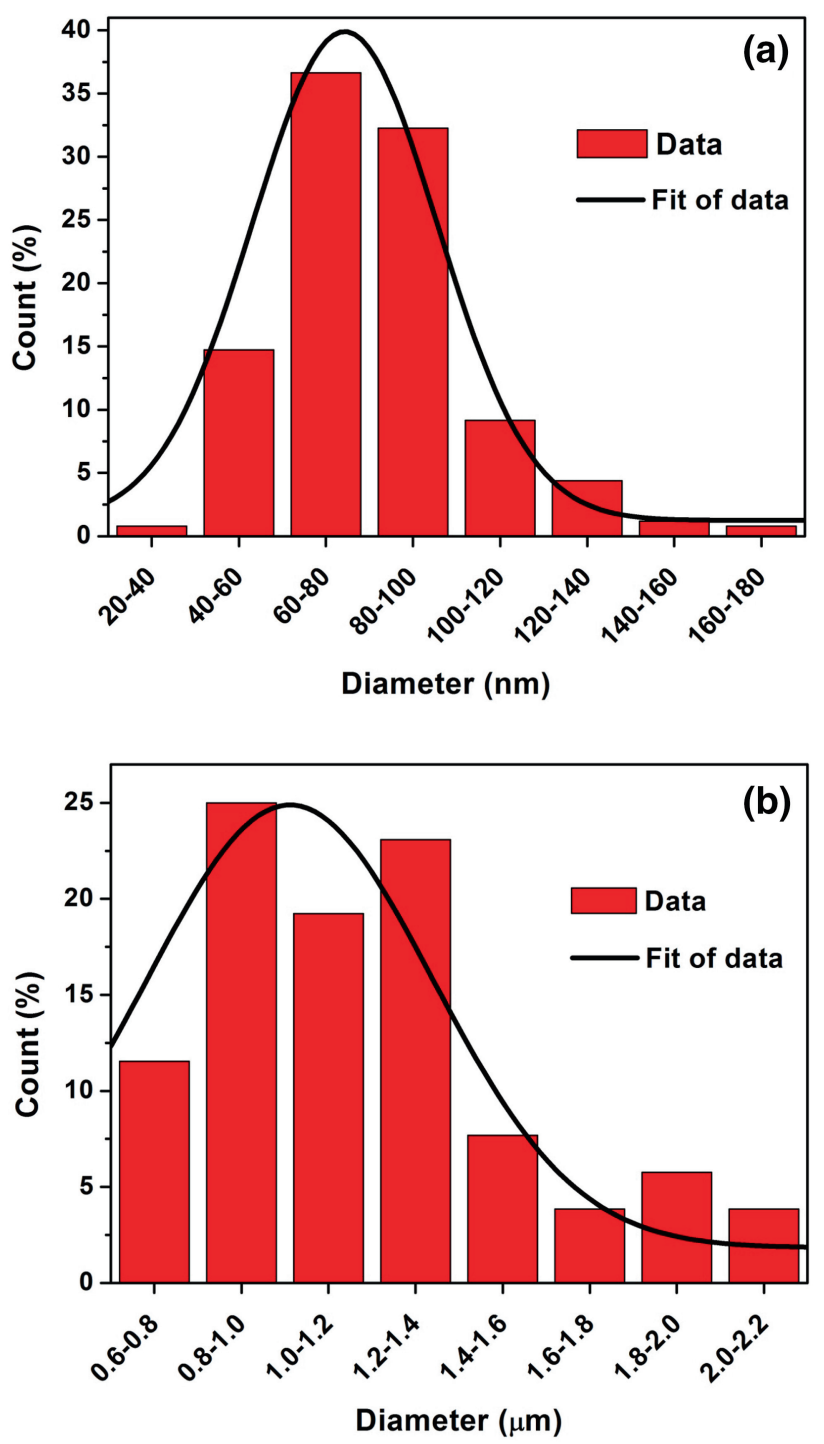

Figure 3. Particle size distributions of $\mathrm{ZnO}$ films prepared from commercial $\mathrm{ZnO}$ NPs (a) compared with $\mathrm{ZnO}$ aggregation (b).

clear based on the $\mathrm{Zn}$ and $\mathrm{O}$ peaks. The $\mathrm{Zn} / \mathrm{O}$ atomic ratio was 0.86 , indicating a fair $\mathrm{ZnO}$ formation. However, a $\mathrm{Zn} / \mathrm{O}$ ratio less than 1.0 may indicate non-purity in the $\mathrm{ZnO}$ formation. It should be noted that the unlabelled peak around $2.2 \mathrm{keV}$ is ignored because it is the $\mathrm{Au}$ peak from the Au coating to assist with better SEM operation $[18,19]$.

\subsection{XRD analysis}

The crystal structure of the $\mathrm{ZnO}$ aggregate films was investigated using XRD analysis and the diffraction peaks are shown in figure 6 . The detected peaks correspond to the hexagonal wurtzite structure of $\mathrm{ZnO}$ (JCPDS no. 36-1451) [20]. This result indicates that the chemical reaction can transform the mixed solution phase to $\mathrm{ZnO}$ [21]. To estimate the crystalline 

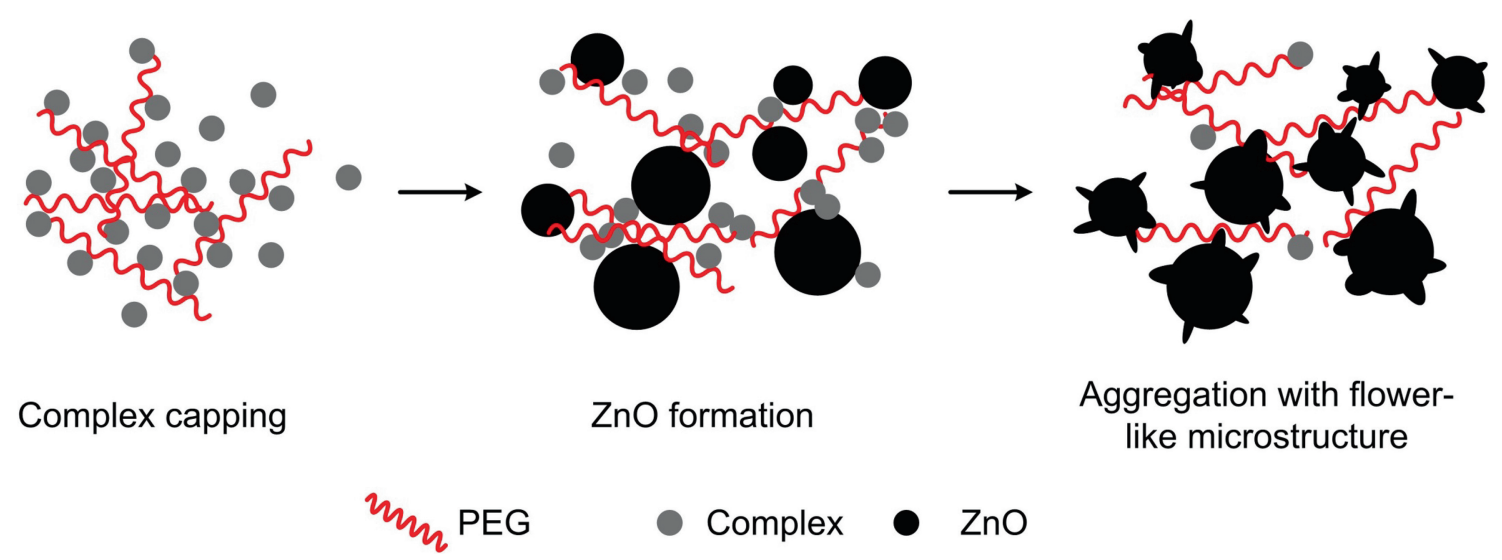

Figure 4. Growing mechanisms of $\mathrm{ZnO}$ aggregate films with PEG modification.

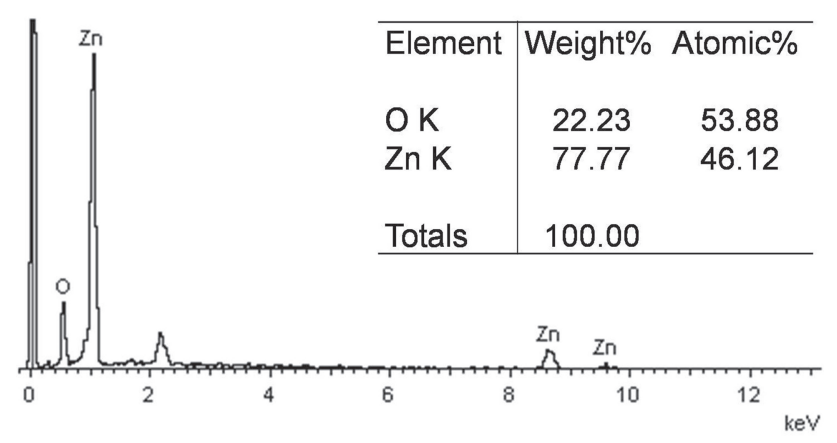

Figure 5. Chemical compositions of $\mathrm{ZnO}$ aggregate films.

size $(D)$ of the $\mathrm{ZnO}$ aggregate films, a calculation was carried out based on the Scherrer's formula [20,22]:

$$
D=K \lambda /(\beta \cos \theta)
$$

where $K$ is a constant (0.89), $\lambda$ is the wavelength of the $\mathrm{X}$ ray source $(1.5406 \AA), \beta$ is the full width at half-maximum intensity of the peak and $\theta$ is the Bragg angle for the measured peak. For better calculation, the crystalline size was calculated from the three high-intensity peaks of (100), (002) and (101) [23], and the average size was $20.21 \pm 1.35 \mathrm{~nm}$. The result indicated that the crystal structure of the $\mathrm{ZnO}$ aggregate films was a nanostructure.

\subsection{Raman measurement}

Raman spectroscopy was performed to investigate molecular vibration and chemical structure. It was performed using interactive light to observe the disorder states or defects in $\mathrm{ZnO}$, which cannot be detected using XRD. The $\mathrm{ZnO}$ formation can be analysed from the group theory of vibration modes according to the Raman shift shown in figure 7. The dominant peak at $438 \mathrm{~cm}^{-1}$ represents the $\mathrm{ZnO}$ nonpolar optical phonon $\mathrm{E}_{2}$ mode, which corresponds to the characteristic peak of the

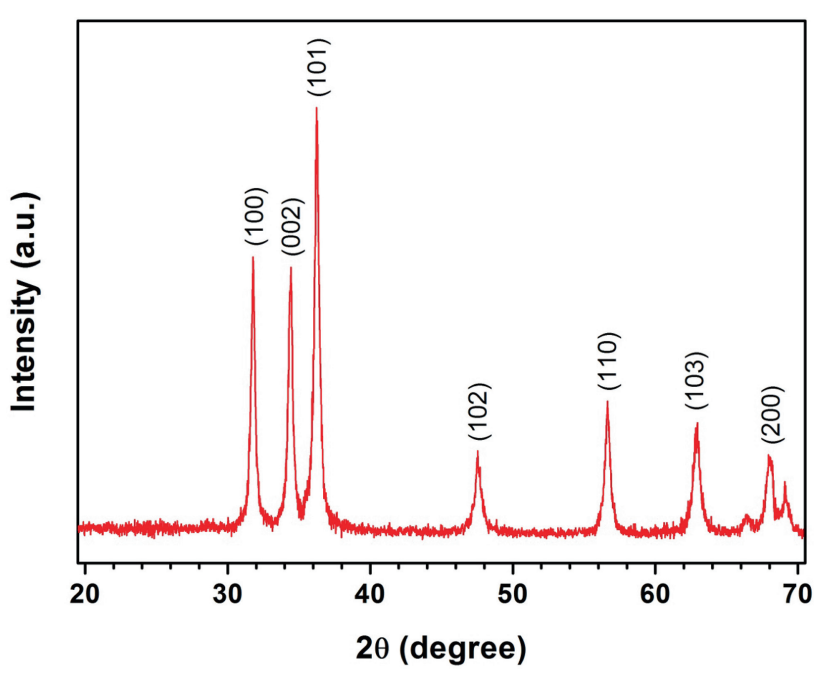

Figure 6. $\mathrm{XRD}$ patterns of $\mathrm{ZnO}$ aggregate films.

Raman active mode of the wurtzite hexagonal $\mathrm{ZnO}$ structure [24]. The weak peak at $381 \mathrm{~cm}^{-1}$ represents the transverse optical modes of $\mathrm{A}_{1 \mathrm{~T}}$. The detected peak at $333 \mathrm{~cm}^{-1}$ represents the boundary phonon $\mathrm{E}_{2 \mathrm{H}}-\mathrm{E}_{2 \mathrm{~L}}$ mode. The broad peak around $580 \mathrm{~cm}^{-1}$ represents the quasi-LO mode, because the peak location is found between $\mathrm{A}_{1 \mathrm{LO}}\left(574 \mathrm{~cm}^{-1}\right)$ and $\mathrm{E}_{1 \mathrm{LO}}$ $\left(591 \mathrm{~cm}^{-1}\right)$. The quasi-LO mode attributes the disorder state or defect in the $\mathrm{ZnO}$ [25]. Thus, it can be interpreted that impurity of the $\mathrm{ZnO}$ aggregate films occurred which was in agreement with the $\mathrm{Zn} / \mathrm{O}$ atomic ratio.

\subsection{Photovoltaic characteristics}

To evaluate the performance of the $\mathrm{ZnO}$ aggregate films for DSSC application, commercial ZnO NP films were used as the reference cell. For each condition, solar cell devices were repeatedly fabricated with five samples. The current density $(J) v s$. voltage $(V)$ curve of the measured photovoltaic characteristics at standard measurement is shown in figure 8 and 


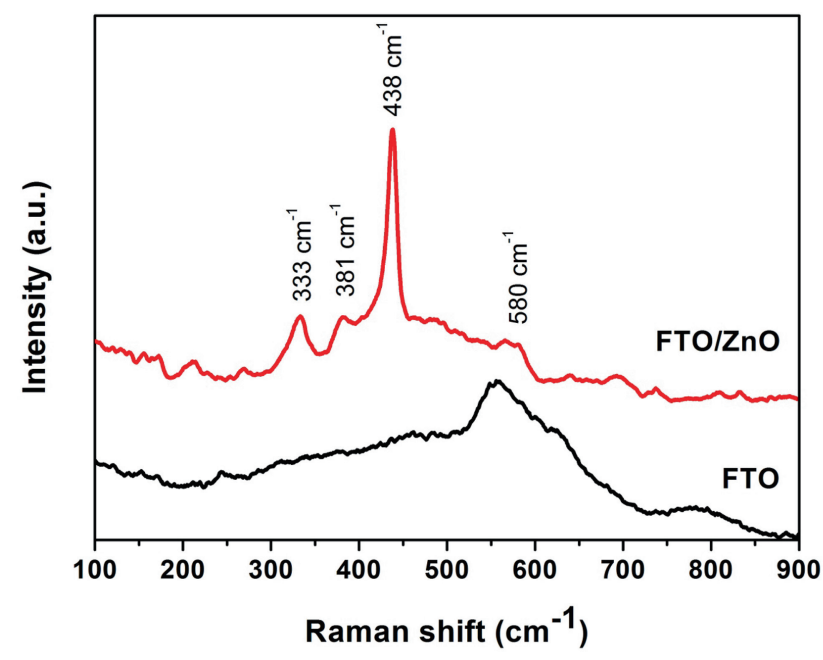

Figure 7. Raman shift of $\mathrm{ZnO}$ aggregate films prepared on the FTO substrate.

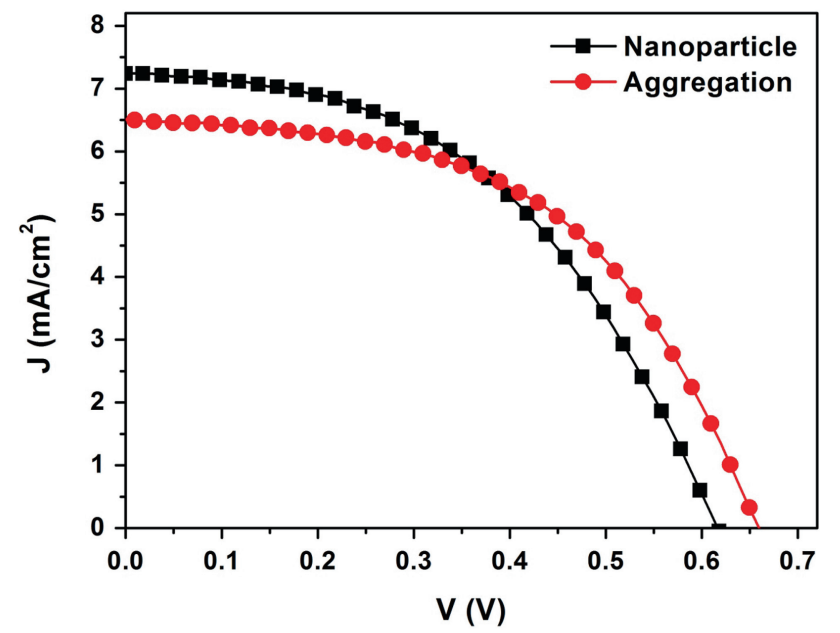

Figure 8. Current density vs. voltage of DSSCs fabricated with different $\mathrm{ZnO}$ photoelectrodes.

the corresponding photovoltaic parameters are summarized in table 1 . The short-circuit current density $\left(J_{\mathrm{sc}}\right)$ of the DSSC fabricated using the $\mathrm{ZnO}$ aggregate films was lower than that of the $\mathrm{ZnO}$ NP-based DSSC. This result was caused by lower dye adsorption for the $\mathrm{ZnO}$ aggregate films as can be seen from the lower dye adsorption spectra in figure 9a. Quantitative comparison of dye adsorption was evaluated from the
UV-Vis-NIR result and calculated using the Beer-Lambert law [26]:

$$
A=c \varepsilon L
$$

where $A$ is the absorbance, $c$ is the dye concentration, $\varepsilon$ is the molar extinction coefficient of $\mathrm{N} 719$ dye $\left(\varepsilon=14,100 \mathrm{M}^{-1}\right.$ $\mathrm{cm}^{-1}$ at $\lambda=515 \mathrm{~nm}$ ) and $L$ is the path length of the measured dye. The calculated dye adsorption values were $3.56 \times 10^{-8}$ and $4.22 \times 10^{-8} \mathrm{~mol} \mathrm{~cm}^{-2}$ for the $\mathrm{ZnO}$ aggregate films and $\mathrm{ZnO}$ NP films, respectively. The dye adsorption of the $\mathrm{ZnO}$ aggregate films was quite lower than that of the $\mathrm{ZnO} N P$ films. It is well-known that the reason for this low dye adsorption is due to the low surface-to-volume ratio of the larger particle, which reduces the effective area for the dye molecules to adhere to the $\mathrm{ZnO}$ surface. By assuming a spherical shape for both films, the surface-to-volume ratio of the $\mathrm{ZnO}$ aggregate films was $10^{-1}$ times lower than that of the $\mathrm{ZnO}$ NP films but there was not much difference in the dye adsorption. It was noted that the dye adsorption of $\mathrm{ZnO}$ aggregate films was not directly correlated with the surface-to-volume ratio. The dye adsorption of the $\mathrm{ZnO}$ aggregate films was higher than that for a comparatively calculated surface-to-volume ratio. This effect can be explained by the small amount of $\mathrm{ZnO}$ NPs attached over the surface of the flower-like microstructure perhaps improving the surface area of the $\mathrm{ZnO}$ aggregate films as seen from the high magnification image in figure $2 \mathrm{~d}$. These small $\mathrm{ZnO}$ NPs have potential to gain dye adsorption in this case. Even though the $\mathrm{ZnO}$ aggregate film-based DSSCs had a lower $J_{\mathrm{sc}}$, the open-circuit voltage $\left(V_{\mathrm{oc}}\right)$ and fill factor $(\mathrm{FF})$ were higher in values. The results indicated an improvement in $V_{\mathrm{oc}}$ and FF. This improvement led to a PCE enhancement of $2.24 \%$, which was higher than that for the ZnO NP film-based DSSCs $(2.12 \%)$.

To understand the improvement in $V_{\mathrm{oc}}$, dark current was measured as shown in figure $9 \mathrm{~b}$. It could be clearly seen that the $\mathrm{ZnO}$ onset voltage of the aggregate film-based DSSCs was higher than that of the $\mathrm{ZnO}$ NP film-based DSSCs which corresponded to an improvement in the $V_{\mathrm{oc}}$. The increase in the $V_{\mathrm{oc}}$ could be attributed to maintaining a high electron concentration in the conduction band (CB) of the $\mathrm{ZnO}$ aggregate films. On the other hand, the lower $V_{\text {oc }}$ of the $\mathrm{ZnO} \mathrm{NP}$ film-based DSSCs was due to the electron loss during the transport process. In brief, electrons in the ground state of the dye molecules will increase the energy level to the excited state after absorbing energy from incident sunlight. These excited electrons are transferred from dye molecules to the

Table 1. Photovoltaic parameters of DSSCs.

\begin{tabular}{lcccccc}
\hline Films & $J_{\mathrm{sc}}\left(\mathrm{mA} \mathrm{cm}^{-2}\right)$ & $V_{\mathrm{oc}}(\mathrm{V})$ & FF & PCE $(\%)$ & $R_{\mathrm{S}}(\Omega)$ & $R_{\mathrm{sh}}(\Omega)$ \\
\hline NPs & $7.24 \pm 0.11$ & $0.61 \pm 0.01$ & $0.48 \pm 0.01$ & $2.12 \pm 0.03$ & $40.57 \pm 0.34$ & $580.44 \pm 77.63$ \\
Aggregates & $6.51 \pm 0.09$ & $0.66 \pm 0.01$ & $0.52 \pm 0.01$ & $2.24 \pm 0.02$ & $36.66 \pm 0.39$ & $904.38 \pm 103.08$ \\
\hline
\end{tabular}



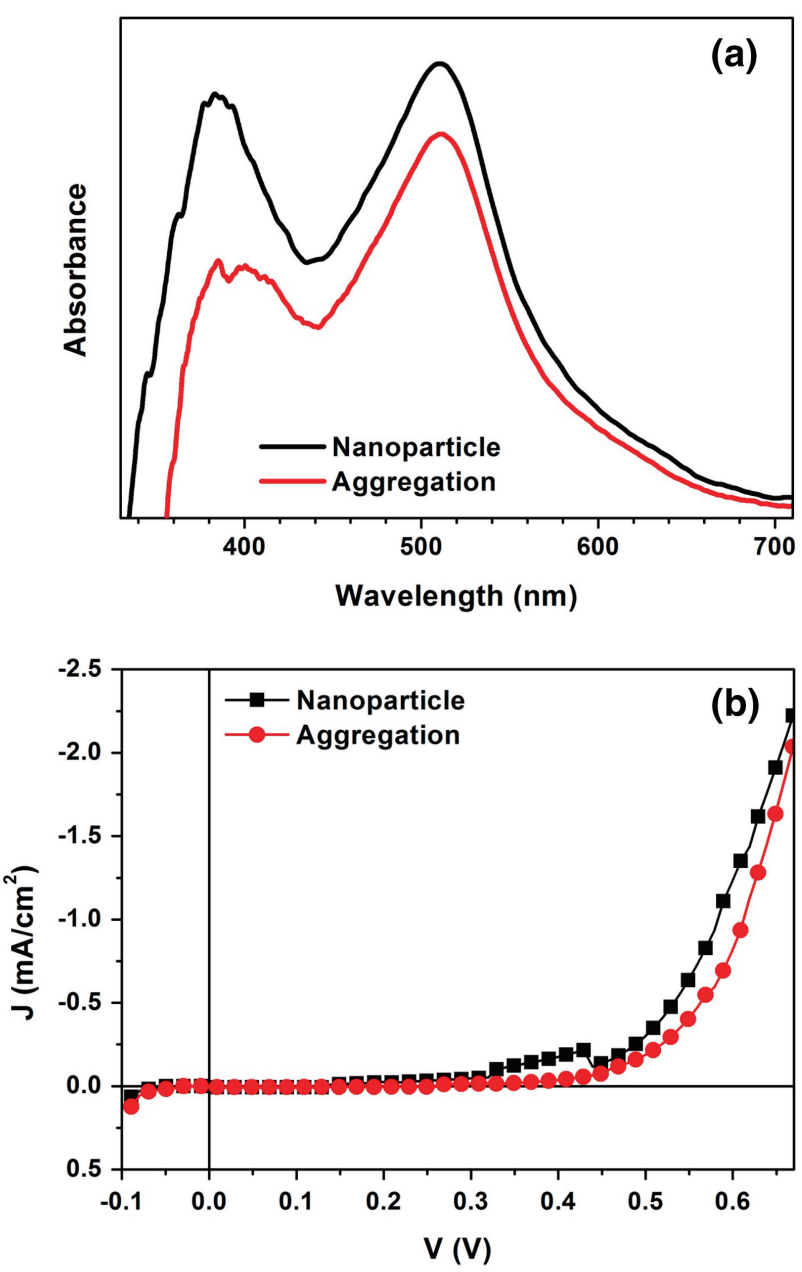

Figure 9. Dye adsorption of N719 extracted from different $\mathrm{ZnO}$ photoelectrodes (a) and photovoltaic characteristics under dark conditions (b).

$\mathrm{CB}$ of $\mathrm{ZnO}$, extending the voltage. Next, the electrons are continuously transported from one particle to another particle until reaching an external load. However, some electrons may be lost during the transport process due to the electron scattering effect. The electron scattering effect occurs when an electron hits a grain boundary of $\mathrm{ZnO}$ and it cannot pass to another particle. The scattered electrons will immediately recombine with an electrolyte on the surface of $\mathrm{ZnO}$ [27]. For $\mathrm{ZnO}$ NP films with small particles, there are many grain boundaries that can scatter electrons when moving from one particle to another particle. Moreover, the connection of ZnO NPs may be an inconvenient transport pathway because the surface contact of spherical particles is not appropriate. Thus, the electron scattering effect may occur due to the small particle size of ZnO NPs. It is believed that the scattering effect could be solved by a large particle size (the $\mathrm{ZnO}$ aggregate films with flower-like microstructures). The large particle size can reduce the grain boundary and the flower-like microstructure can perform as an electron transport pathway. Therefore, it is believed that $\mathrm{ZnO}$

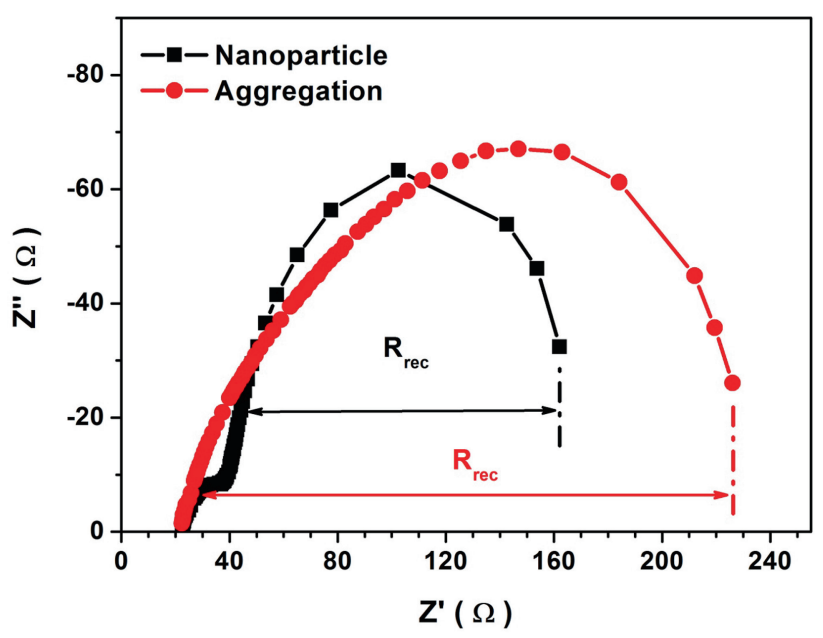

Figure 10. EIS of the DSSCs fabricated with different $\mathrm{ZnO}$ photoelectrodes.

aggregate films have the potential to maintain electrons in the $\mathrm{CB}$ of $\mathrm{ZnO}$ which can increase the $V_{\text {oc }}$. In addition, the improved dark current not only increases the $V_{\text {oc }}$ but also increases the FF simultaneously. The increase in the FF is believed to be due to a change in the internal resistances including the decreased series resistance $\left(R_{\mathrm{S}}\right)$ and increased shunt resistance $\left(R_{\mathrm{sh}}\right)$ as seen in table 1 . These results confirm that the large particle size of $\mathrm{ZnO}$ aggregate films with flower-like microstructures can provide better electron transport, which is reflected in the decreased $R_{\mathrm{s}}$. Moreover, the increased $R_{\mathrm{sh}}$ can be assumed to indicate that the electron scattering effect or the electron recombination effect is reduced.

To deeply investigate the internal dynamic exchange behaviour, EIS was performed under dark conditions with a forward bias of $-V_{\text {oc }}$ to observe any electron recombination resistance $\left(R_{\mathrm{rec}}\right)$ as a means to investigate the electron recombination effect. The measurement results are shown in figure 10. The resistance can be estimated from the diameter of the semicircle of the real part ( $Z^{\prime}$-axis). Generally, the small and large semicircles refer to the total resistance $\left(R_{\mathrm{t}}\right)$ and $R_{\text {rec }}$ of DSSCs, respectively. Note that $R_{\mathrm{t}}$ cannot be clearly observed because it has a very small value compared with the large semicircle. However, it is enough to focus only on the large semicircle for the evaluation of $R_{\text {rec }}$. A large $R_{\text {rec }}$ value means that most electrons can be transported through the external load with low recombination, while a small $R_{\text {rec }}$ means the opposite. The EIS results showed that the $R_{\text {rec }}$ of the DSSC fabricated with the $\mathrm{ZnO}$ aggregate films was greater than that of the $\mathrm{ZnO} \mathrm{NP}$ films, which can be interpreted as most electrons are transported through the external load. The result may be due to the reduction in the electron recombination effect [28], which can be explained by a reduction in the transfer coefficient $(B)$ from the following relationship [29]:

$$
R_{\mathrm{rec}}=R_{0} \exp \left(-e B V / k_{\mathrm{B}} T\right)
$$


where $R_{0}$ is a constant, $e$ is the electron charge, $V$ is the applied voltage, $k_{\mathrm{B}}$ is the Boltzmann constant and $T$ is the absolute temperature. The increase in $R_{\text {rec }}$ may be a result of the reduced transfer coefficient, when the other parameters are not changed. In this case, the reduced transfer coefficient for electron recombination can be assumed due to better forward electron transport provided by the linkage of the flower-like microstructure. The improved electron transport efficiency is normally believed to reduce the probability density of electron recombination. Moreover, a reduction in the transfer coefficient can decrease the recombination rate $\left(k_{\mathrm{r}}\right)$ which results in an increase in $V_{\mathrm{oc}}$, according to the following relationship $[7,30]$ :

$$
V_{\mathrm{oc}}=\left(k_{\mathrm{B}} T / e\right) \ln \left(I_{\mathrm{inj}} / n_{\mathrm{cb}} k_{\mathrm{r}} c\right)
$$

where $I_{\text {inj }}$ is the injected electron current, $n_{\mathrm{cb}}$ is the electron density in the $\mathrm{CB}$ of the photoelectrode and $c$ is the concentration of triiodide species in the electrolyte. Thus, the increased $R_{\text {rec }}$ can keep most of the injected electrons in the $\mathrm{CB}$ of the $\mathrm{ZnO}$ which results in an increased $V_{\mathrm{oc}}$. Nevertheless, it can support the electron transport effectively due to the high electron density and reduced electron recombination which is reflected in the decreased $R_{\mathrm{s}}$ and increased $R_{\mathrm{sh}}$. The increase in $R_{\mathrm{rec}}$ not only increases $V_{\mathrm{oc}}$, but also improves internal resistances (decreased $R_{\mathrm{S}}$ and increased $R_{\text {sh }}$ ) concurrently. From the results, it is believed that the aggregate formation with a flower-like microstructure can improve the linkage within the $\mathrm{ZnO}$ aggregate photoelectrode. The improved linkage has the ability to provide better electron transport and to prevent electron scattering as illustrated in figure 11. The large particle size of $\mathrm{ZnO}$ aggregates is believed to reduce the scattering boundaries, compared with the small particle size of ZnO NPs [31]. Moreover, the flower-like microstructure is believed to improve the electron transport efficiency at the same time. Therefore, most electrons have better potential to transport through an external load for a large particle size of $\mathrm{ZnO}$ aggregates with flowerlike microstructures compared with the small size of the NPs. For overall photovoltaic performance comparison, there were small differences in the photovoltaic parameters between $\mathrm{ZnO}$ NP- and $\mathrm{ZnO}$ aggregate-based DSSCs. However, the $\mathrm{ZnO}$ aggregates with flower-like microstructures synthesized using a simple precipitation with polymer modification shows an interesting development method for DSSC application due to its low cost and being a simple process. For $\mathrm{ZnO}$ NPbased DSSCs, high purity ZnO NPs must be purchased at a high cost or synthesized using effective technology. Then, the addition of $\mathrm{ZnO}$ NPs into a polymer solution, binder solution or several solvents is carried out to transform the viscous $\mathrm{ZnO}$ NP precursors before the coating process. Next, the viscous precursors are coated onto a substrate to form precursor films and finally annealed to form $\mathrm{ZnO}$ NP films. All these steps make the synthesis of $\mathrm{ZnO}$ NP films a complicated process. On the other hand, the $\mathrm{ZnO}$ aggregates with flower-like
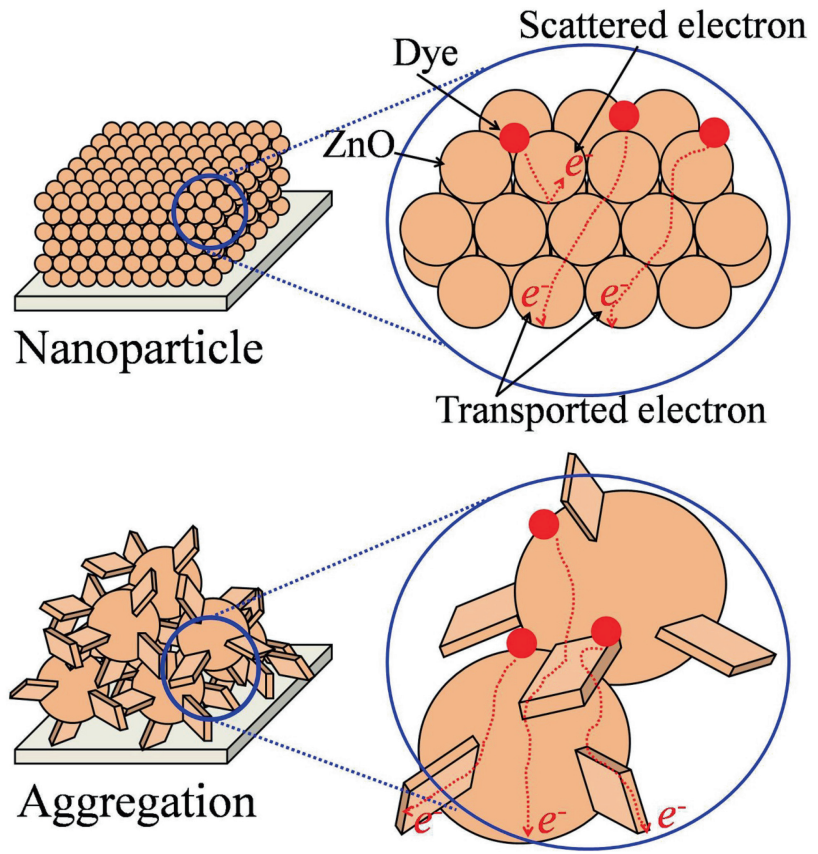

Figure 11. An illustration of electron transport pathway for different $\mathrm{ZnO}$ structures.

microstructures is an interesting simpler method at low cost. After the synthesis of the $\mathrm{ZnO}$ aggregates, the synthesized $\mathrm{ZnO}$ aggregates can be immediately coated onto the substrate and annealed to obtain $\mathrm{ZnO}$ aggregate films. Therefore, the $\mathrm{ZnO}$ aggregates with flower-like microstructures synthesized using simple precipitation with polymer modification can be considered as an alternative method for DSSC fabrication which is a low cost and a simple process to obtain photovoltaic parameters similar to those for ZnO NP-based DSSCs. Furthermore, the enhanced photovoltaic performance of $\mathrm{ZnO}$ aggregate-based DSSCs may be achieved by reducing from microstructure to nanostructure for increasing dye molecule adsorption which should be further investigated.

\section{Conclusion}

The $\mathrm{ZnO}$ aggregates with flower-like microstructures was successfully synthesized using a simple precipitation with polymer modification. The viscous $\mathrm{ZnO}$ precursor was coated onto the substrate and annealed. Large size $\mathrm{ZnO}$ aggregate films with flower-like microstructures were finally obtained. The chemical composition ratio of $\mathrm{Zn} / \mathrm{O}$ revealed a fair $\mathrm{ZnO}$ formation. The hexagonal wurtzite structure of $\mathrm{ZnO}$ was confirmed using the XRD and Raman results. For DSSC application, the DSSC fabricated with the $\mathrm{ZnO}$ aggregate films as a base exhibited a lower current density compared with the $\mathrm{ZnO}$ NP-based one due to lower dye adsorption. However, the improved linkage of $\mathrm{ZnO}$ aggregate films with flower-like microstructures play an important role of an express pathway 
to provide better electron transport and reduce electron scattering in the DSSCs. This improvement finally results in an enhanced photovoltaic performance. Therefore, the synthesis of the $\mathrm{ZnO}$ photoelectrode using polymer modification has the potential to modify the linkage of $\mathrm{ZnO}$ aggregates with flower-like microstructures, and the modified structure can provide an express pathway for electron transport improvement in DSSCs.

\section{Acknowledgements}

This work was supported by the Faculty of Liberal Arts and Science, Kasetsart University Kamphaeng Saen Campus, Nakhon Pathom. The authors would like to kindly acknowledge the Applied Physics Research Laboratory (APRL), Department of Physics and Materials Science, Faculty of Science, Chiang Mai University for materials and device measurements.

\section{References}

[1] Xu J, Fan K, Shi W, Li K and Peng T 2014 Sol. Energy 101 150

[2] Elumalai N K, Vijila C, Jose R, Uddin A and Ramakrishna S 2015 Mater. Renew. Sustain. Energy 41

[3] Shalini S, Balasundara Prabhu R, Prasanna S, Mallick T K and Senthilarasu S 2015 Renew. Sustain. Energy Rev. 511306

[4] Anta J A, Guillén E and Tena-Zaera R 2012 Phys. Chem. C 116 11413

[5] Deepak T G, Anjusree G S, Thomas S, Arun T A, Nair S V and Sreekumaran Nair A 2014 RSC Adv. 417615

[6] Wan K, Wu F, Dou Y, Fang L and Mao C 2016 J. Alloys Compd. 680373

[7] Song L, Du P, Xiong J, Ko F and Cui C 2015 Electrochim. Acta 163330

[8] Sutthana S, Wongratanaphisan D, Gardchareon A, Phadungdhitidhada S, Ruankham P and Choopun S 2016 Surf. Coat. Technol. 30630

[9] Moungsrijun S, Sujinnapram S, Choopun S and Sutthana S 2017 Monatsh. Chem. 1481191
[10] Mahdavi R and Talesh S S A 2017 Adv. Powder Technol. 28 1418

[11] Kabongo G L, Mhlongo G H, Mothudi B M, Hillie K T, Mbule P S and Dhlamini M S 2017 J. Lumin. 187141

[12] Petruf K, Panak O, Valenta J and Nemec P 2017 Ceram. Int. 43 5223

[13] Duan J, Huang X and Wang E 2006 Mater. Lett. 601918

[14] Fageria P, Gangopadhyay S and Pande S 2014 RSC Adv. 4 24962

[15] Wang F, Qin X, Zhu D, Meng Y, Yang L and Ming Y 2014 Mater. Lett. 117131

[16] Zheng W, Ding R, Yan X and He G 2017 Mater. Lett. 20185

[17] Dhiman N, Markandeya, Singh A, Verma N K, Ajaria N and Patnaik S 2017 J. Colloid. Interface Sci. 493295

[18] Dang H, Li B, Li C, Zang Y, Xu P, Zhao X et al 2018 Electrochim. Acta 26724

[19] Shahini P and Ashkarran A A 2018 Colloid. Surface A 537 155

[20] Wiranwetchayan O, Promnopas W, Hongsith K, Choopun S, Singjai $\mathrm{P}$ and Thongtem S 2016 Res. Chem. Intermed. 42 3655

[21] Wongrat E, Chanlek N, Chueaiarrom C, Samransuksamer B, Hongsith N and Choopun S 2016 Sens. Actuat. A 251188

[22] Musavi Gharavi P S and Mohammadi M R 2015 Sol. Energy Mater. Sol. Cells 137113

[23] Al-Kahlout A 2015 J. Assoc. Arab. Univ. Basic Appl. Sci. 17 66

[24] Wang H, Wang C, Chen Q, Ren B, Guan R, Cao X et al 2017 Appl. Surf. Sci. $\mathbf{4 1 2} 517$

[25] Gurylev V, Su C Y and Perng T P 2017 Appl. Surf. Sci. 411 279

[26] Sutthana S, Wongratanaphisan D, Gardchareon A, Phadungdhitidhada S, Ruankham P and Choopun S $2016 \mathrm{~J}$. Nanomater. 20167403019

[27] Justin Raj C, Karthick S N, Hemalatha K V, Kim S K, Kim B, Yu K H et al 2014 Appl. Phys. A: Mater. 116811

[28] Ahmad W, Mehmood U, Al-Ahmed A, Al-Sulaiman F A, Aslam M Z, Kamal M S et al 2016 Electrochim. Acta 222 473

[29] Zheng J W, Mo L E, Chen W C, Jiang L, Ding Y C, Ding Y et al 2017 Electrochim. Acta 23238

[30] Fadadu K B and Soni S S 2013 Electrochim. Acta 88270

[31] Hwang T-H, Kim W-T and Choi W-Y 2017 J. Nanosci. Nanotechnol. 174812 